\title{
Acessibilidade e Ludicidade no Ensino de Computação
}

\author{
Rayana R. Bonfanti ${ }^{1}$, Ernandes S. Santos ${ }^{1}$, Mário da C. Maselli ${ }^{1}$, Josualdo Dias ${ }^{1}$ \\ ${ }^{1}$ Instituto Federal de Educação, Ciência e Tecnologia da Bahia - Campus Porto Seguro - \\ Rod br 367, R. José Fontana, 1, Porto Seguro - BA, 45810-000. \\ \{rayanabonfanti,ernandes2149,mariokatt.dg\}@gmail.com, josualdodias@ifba.edu.br
}

\begin{abstract}
The scenario of inclusive education is still precarious nowadays, especially in Computer Science teaching. Thus, the methods and practices that bring accessibility are forms of inclusion for better development of teaching and learning. Therefore, this article aims to present the experience and discussions of the application and contribution of playful games with accessibility for the visually impaired in computer science teaching. An activity was applied to students in the field of Computer Science based on cognition stimulation, exercises of Computational Thinking, and promoting accessibility to computer science education. The application can lead to a collaborative activity with an emphasis on accessibility for teaching and learning in a playful way.
\end{abstract}

Resumo. O cenário da educação inclusiva ainda é precário nos dias atuais, sobretudo, no ensino de Computação. Assim, os métodos e práticas que trazem a acessibilidade, são formas de inclusão e melhor desenvolvimento no ensino e aprendizado. Este artigo tem como objetivo apresentar e discutir a experiência da aplicação e contribuição de jogos lúdicos com acessibilidade para deficientes visuais no ensino de Computação. Uma atividade foi aplicada para estudantes da área de Computação, tendo como base o estimulo à cognição, exercício do Pensamento Computacional e promoção da acessibilidade para o ensino de Computação. A aplicação pode conduzir a uma atividade colaborativa com ênfase na acessibilidade, para o ensino e aprendizado de forma lúdica.

\section{Introdução}

Pensar em novas formas de ensino pode ser o caminho à universalização do acesso à educação para uma nação com tantas desigualdades. Segundo o IBGE (2019), a projeção da população brasileira era de aproximadamente 210,1 milhões de habitantes em 2019, dos quais $17,42 \%$ estavam matriculados na educação básica em escolas públicas regulares, sendo 0,49\% das matrículas se encontravam na educação inclusiva, conforme MEC (2019). Por conseguinte, a pesquisa nacional de saúde - IBGE (2015), identificou que, $6,2 \%$ dos brasileiros têm algum tipo de deficiência, além disso, a deficiência visual com $3,6 \%$ é a que se apresenta com maior incidência.

Para atender essa parcela da população, de acordo com a Constituição (1998) que, garante o acesso à educação de qualidade, como um direito de todos e um dever do Estado brasileiro, conforme Art. 5. Dessa forma, a educação foi normatizada pela Lei de Diretrizes e Bases da Educação, que entre outros princípios está pautada nos "[...]ideais de solidariedade humana.", da "igualdade de condições para o acesso e permanência na escola[...]", conforme Art. 1 [Brasil 1996]. Por outro lado, o ensino de computação não 
está plenamente normatizado no Brasil, como paliativo a essa lacuna regulamentadora, existe a Base Nacional Comum Curricular (BNCC), que prevê o ensino de tecnologias com os componentes curriculares, além de prognosticar o desenvolvimento do pensamento computacional como competência básica. Considera também que, a igualdade educacional sobre a qual as singularidades devem ser consideradas e atendidas, conforme Brasil (2017).

Este artigo tem como objetivo apresentar a experiência do planejamento e aplicação de uma oficina denominada Jogos para Ensino de Computação, e discutir as contribuições de jogos com acessibilidade para deficientes visuais no ensino de Computação. Além da introdução, o artigo foi estruturado da seguinte maneira, na Seção 2 apresenta o alinhamento do pensamento computacional com a computação desplugada, e acessibilidade com Jogos Lúdicos para o Ensino de Computação. Na Seção 3 apresenta o processo de elaboração da oficina, destacando as produções dos jogos e práticas utilizadas. Na Seção 4 são apresentados os resultados e discussões. Por fim, na Seção 5 são colocadas as considerações finais.

\section{Alinhando o Pensamento Computacional com a Computação Desplugada}

O ambiente agradável favorecido pelos jogos pode melhorar a motivação dos estudantes, uma vez que, à medida que as reprovações continuam ocorrendo, a motivação dos estudantes declina [Berssanette and Francisco 2018]. Sob a ótica dos métodos e práticas de ensino, os métodos tradicionais não têm propiciado habilidades desejáveis, formação crítica e promoção do aprendizado adequado [Gavaza et al. 2018]. Logo, faz-se necessário o aprimoramento de metodologias de ensino, para que possam oportunizar ao estudante um processo de aprendizagem favorável. Para tanto, a ludicidade dos jogos vêm facilitando o ensino, como também, a Computação Desplugada (CD), meios pelos quais não precisa, necessariamente, utilizar dispositivos eletrônicos para ensinar conteúdos de computação.

$\mathrm{Na}$ abordagem do Pensamento Computacional (PC), consideramos que, o ser humano nasce com inúmeras habilidades, dentre as quais buscamos evidenciar o PC na aplicação das atividades em oficina de jogos. Segundo Wing (2006), "o pensamento computacional é uma habilidade fundamental para todos, não apenas para os cientistas da computação. Para leitura, escrita e aritmética, devemos adicionar a habilidade destacada à capacidade analítica de cada criança.”.

O desenvolvimento do PC pode auxiliar o processo de aprendizagem da Computação, como também em outras áreas do âmbito educacional e profissional. Diante essa situação, alguns trabalhos são embasados nessa perspectiva, Silva et al. (2018) trazem um jogo chamado CriptoLAB, cuja finalidade é desenvolver o PC por meio da $\mathrm{CD}$ para ensinar criptografia e sequências lógicas. Outros trabalhos também envolvem a utilização de jogos, computação desplugada e PC para ensino da Computação [Pereira et al. 2019], [Santos and Figueiredo 2016], [Reis et al. 2018], [Nery and Sá 2019].

No que se refere a CD por Bell et al. (2011), autores do livro Computer Science Unplugged (Ciência da Computação Desplugada) ${ }^{1}$, apresentam um acervo de práticas para ensinar conteúdo de computação sem o uso do computador, possibilitando a utilização das práticas em diversas escolas e lugares com pouca infraestrutura. Em relação

\footnotetext{
${ }^{1}$ Site do projeto de Computação Desplugada: https://csunplugged.org/
} 
às habilidades do PC, Pereira et al. (2019) indaga que, "ao aliar pensamento computacional e atividades desplugadas, pode-se exercitar habilidades diversas como resolução de problemas, abstração, decomposição, raciocínio algorítmico e avaliação".

A ludicidade dos jogos possibilitam aliar o PC e a Computação Desplugada, pois trazem além da diversão, motivação e conhecimentos dos conteúdos trabalhados. Ademais, a interação social pode ser despertada como forma de colaborar com a aprendizagem, assim aprimorando os conhecimentos, capacidades, atitudes e habilidades que podem ser tratadas como imaginação, diversão, aceitação de regras, desenvolvimento do raciocínio lógico, entre outros [Guarda and Goulart 2018]. Segundo Vieira et al. (2019), "o uso de jogos provê feedbacks relativamente imediatos e constantes, que inclui informações sobre precisão (por exemplo, se uma questão está certa ou errada) e fornece orientação de como está ocorrendo o processo de aprendizagem do conteúdo".

\subsection{Acessibilidade com Jogos Lúdicos para o Ensino de Computação}

Sobre o aspecto da acessibilidade com jogos para deficientes visuais, sobretudo no ensino de Computação, há uma lacuna na Educação Inclusiva, no contexto em que 6,2\% da população têm algum tipo de deficiência e apenas 0,49\% estão nas Instituições de Ensino. Logo, faz-se necessário pensar e propor meios que, aplicados nas escolas contribuam com os atendimentos dos estudantes dado as suas particularidades, para que estes possam usufruir o aprendizado com mais eficácia [Nery and Sá 2019]. Mediante essa necessidade de inclusão e trazer a acessibilidade em conteúdos de computação, Cruz et al. (2017) desenvolveram um aplicativo chamado LibrasTI com objetivo de possibilitar conhecimentos de termos técnicos da área de informática para estudantes com deficiência auditiva.

De acordo com Nery and Sá (2019), “a valorização de expressões lúdicas, tais como o brincar e o uso de jogos, no processo de ensino e aprendizagem, comparece enquanto estratégias exitosas para crianças com deficiência mental, isto objetivando a implementação da educação sensorial". Em questão dessa proposta de ludicidade, Nery and Sá (2019) trazem diversas atividades lúdicas, como, Mosaico Geométrico, Tangram, Cubo Soma, Torre de Hanói, Cubo Mágico e Poligonopolis, para ensino da matemática atendendo todos os estudantes, como também aos deficientes visuais.

Diante o exposto, o emprego de jogos, como meio para o ensino de computação, mostra-se efetivo à inclusão social, uma vez que, diverge dos modelos de ensinos regulares. Em vista disso, faz-se necessária uma postura inovadora por parte dos profissionais da educação nos métodos e práticas de ensino, a fim de atender os desiguais de acordo com suas necessidades.

\section{Experiências de Acessibilidade com Jogos Lúdicos}

A oficina Jogos para Ensino de Computação foi aplicada na Semana Nacional de Ciência e Tecnologia (SNCT) de 2019, para estudantes do Ensino Médio e Superior da área de Computação de um Instituto Federal da Bahia do campus Porto Seguro (IFBA). Essa proposta se tornou possível mediante o componente curricular Metodologias e Práticas de Ensino de Computação III (MPEC-III) da Licenciatura em Computação, na qual os professores de Computação em formação desenvolveram e aplicaram a oficina sob a orientação do docente do referido componente. O docente desse componente, a partir do processo de desenvolvimento e aplicação da oficina, e por meio da aplicação de um 
formulário de satisfação para os participantes, pode avaliar os professores de computação em formação. A sensibilidade a respeito da acessibilidade se inicia no próprio contexto da turma de MPEC-III, onde um dos discente, professor em formação, é uma pessoa cega. Diante disso, a turma foi instigada pelo orientador a: estudar, planejar, desenvolver e aplicar uma proposta para o ensino de computação, na qual permitisse a participação plena de todos os membros da turma.

Para tanto, as atividades se basearam em estimular a cognição, exercitar o PC, estratégias e resolução de problemas, trabalhar a coordenação motora, potencializar a coletividade e promover dinâmicas de acessibilidade para ensino de Computação. Dessa forma, foi dividido em três etapas a explanação: 1) Planejamento e Preparação dos Materiais dos Jogos; 2) Aplicação dos jogos, explicação de conteúdos teóricos e discussões em uma oficina na SNCT e 3) Aplicação dos Formulários.

\subsection{Planejamento e Preparação dos Materiais dos Jogos}

O planejamento ocorreu nos encontros semanais durante as aulas de MPEC-III, no qual foi possível pensar e discutir os métodos e práticas a serem aplicados a fim de atender as exigências desse componente, bem como, as necessidades dos professores em formação.

$\mathrm{Na}$ primeira etapa foram selecionados referências teóricas que versam sobre: PC, ludicidade por meio de jogos, $\mathrm{CD}$ e acessibilidade em diversas áreas de conhecimento. Simultaneamente foram elegidos cinco jogos com acessibilidade possíveis de adaptação. Esses jogos foram submetidos a um filtro pelo professor em formação que é uma pessoa com deficiência visual, esse fato contribuiu efetivamente à adaptação dos jogos para o uso no ensino de Computação para deficientes visuais. Logo, com intuito de facilitar o aprendizado, foi necessário inserir ferramentas que pudessem tornar o tato mais presente e inserir as descrições em braile. Por conseguinte, foi realizada uma oficina piloto para a validação do uso dos jogos e das estratégias adotadas. Para tanto, contou com a participação dos discentes convidados das Licenciaturas em Computação e Química.

Alguns desses jogos, como a Torre de Hanói, Dominó de Osso e Quebra-Cabeça Klotski, não sofreram modificações em suas regras originais, como também não foi realizado intervenções de acessibilidade para deficientes visuais, tendo em vista as características do material de fabricação, tridimensionalidade e acabamentos. Entretanto, outros sofreram adaptações, como o Tabuleiro de Damas e o Jogo de Cartas Uno.

\subsubsection{Tabuleiro de Damas adaptado}

No tabuleiro de damas ${ }^{2}$ foi realizada com relevo em sua superfície, para o tato foi utilizado espuma sintética do tipo EVA, com as dimensões de $40 \mathrm{~cm}$ por $40 \mathrm{~cm}$, as quais representam aproximadamente a área de tato das duas mãos de um jogador. As peças foram pensadas com formatos diferenciados em cubos e cilindros entre si, e com a parte superior revestida em EVA. As regras desse jogo não sofreram alterações significativas, pois quando o jogador fazia a dama, simplesmente invertia a parte superior com EVA para baixo, deixando a parte sem revestimento voltada para cima. Esses formatos e materiais utilizados, possibilitaram uma área palpável cômoda ao tato, além de permitir maior liberdade ao jogador portador de deficiência visual. Dessa forma, o jogador poderá ficar livre de possíveis distrações, focando apenas nas habilidades cognitivas.

\footnotetext{
${ }^{2}$ Link de acesso aos materiais do tabuleiro de damas: https://bit.ly/materiaistabuleirodamas
} 
IX Congresso Brasileiro de Informática na Educação (CBIE 2020)

Anais do XXXI Simpósio Brasileiro de Informática na Educação (SBIE 2020)

\subsubsection{Torre de Hanói}

A Torre de Hanói foi elaborada com fibra de média densidade - MDF com acabamento fino. A base retangular da torre foi desenvolvida com dimensões de $40 \mathrm{~cm}$ por $15 \mathrm{~cm}$, nessa base foram fixadas três hastes arredondadas de madeira com $10 \mathrm{~cm}$ de altura. Os 5 discos tiveram diâmetros de 4, 5, 6, 7 e $8 \mathrm{~cm}$. As dimensões da base e tamanhos dos discos e altura das hastes, tem por finalidade atender a região de tato do jogador.

\subsubsection{Jogo de Cartas Uno Adaptado}

No jogo de Cartas Uno, será dividido em três partes, para melhor explicar sua elaboração: 1) regras do jogo; 2) perguntas do jogo e 3) impressão braile nas cartas. Na primeira parte, as regras do jogo ${ }^{3}$ tiveram que sofrer algumas mudanças, pois determinadas cartas não podiam ser jogadas de acordo com a acessibilidade feita para deficientes visuais. Ademais, algumas cartas quando colocadas em jogo, são acionadas perguntas sobre o conteúdo de Arquitetura de Computadores. Na segunda parte, as perguntas do jogo ${ }^{4}$ foram elaboradas em sua maioria com respostas de certo ou errado, e poucas delas com questões abertas. Na terceira parte, a impressão braile nas cartas ${ }^{5}$ foram feitas de acordo com as cores e as representações de símbolos ou números contidos nelas.

\subsubsection{Dominó de Osso}

Com o dominó de osso foram realizadas partidas diversas, com intervenções apenas para explicar as regras tradicionais quando necessário. O dominó utilizado foi o de peças do tipo osso para melhor identificação. Nesse jogo, as cores dos pontos impressos nas peças do dominó, tiveram sua relevância visual superada pelo relevo ali presente nas peças.

\subsubsection{Quebra-Cabeça Klotski}

No quebra-cabeça klotski foi produzido com base quadrada medindo $30 \mathrm{~cm}$, e suas peças retangulares com tamanhos diferentes, foram elaboradas com madeira e uma peça quadrada. Em relação ao objetivo deste jogo, consiste em mover a peça quadrada para fora do tabuleiro, deslocando as peças retangulares que obstrui a sua passagem.

\subsection{Aplicação dos jogos, explicação de conteúdos teóricos e discussões em uma oficina na SNCT}

Na segunda etapa foram aplicados os jogos em uma oficina que durou cerca de 2 horas na SNCT. Sendo assim, foi disponibilizado pelo evento uma sala de aula, na qual foram separadas as cadeiras em grupos ou duplas para melhor locomoção e uma rotatividade maior dos participantes entre os jogos, como também foi instigado para os discentes se sentarem, e jogar em qualquer uma das modalidades de jogos ofertadas quantas vezes quisessem. Após a interação dos participantes com pelo menos um dos jogos, houve a explicação de conteúdos teóricos durante a aplicação, bem como a ligação entre os jogos e o tema PC e suas habilidades, como: abstração, decomposição e recomposição, raciocínio algorítmico e reconhecimento de padrões, as quais foram trabalhadas de acordo com determinado jogo. Para essa relação, um exemplo prático pode ser mostrado a seguir,

\footnotetext{
${ }^{3}$ Link de acesso as regras do jogo: https://bit.ly/regras-jogo

${ }^{4}$ Link de acesso das perguntas do jogo: https://bit.ly/perguntasjogo

${ }^{5}$ Link de acesso das representações do braile nas cartas: https://bit.ly/brailecartas
} 
a Torre de Hanói possui diversas habilidades presentes nela, que podem ser estimuladas no indivíduo, e algumas podem ser como, reconhecimento de padrão, raciocínio algorítmico, dentre outras. No momento da explanação, as possíveis necessidades de efeitos visuais, tendo como exemplo: apresentação com slides, imagens ou vídeos, foram substituídas pelas experiências obtidas a partir do jogo, para materializar os conceitos intangíveis da computação, que estavam sendo apresentados.

Como forma de avaliação do aprendizado, observou a participação dos estudantes na execução dos jogos, se houve a compreensão das regras dos jogos e conceitos básicos do pensamento computacional aplicados, também verificou o desenvolvimento de estratégias e algoritmos na resolução dos desafios dos jogos. Além disso, foi analisado se o participante conseguiu perceber os conceitos ou padrões em algum dos jogos, como também a utilização da abstração e estruturas de decisão com conectivos lógicos em simulação de jogadas.

\subsection{Aplicação dos Formulários}

Na terceira etapa foi aplicado um formulário ${ }^{6}$, que foi realizado momento após a aplicação da oficina para obter informações sobre a mesma, bem como avaliar a satisfação dos participantes, além da aprendizagem deles, dos jogos e da postura docente presente, também tiveram questões padrões como faixa etária, sexo, escolaridade e se gostariam de participar de alguma oficina semelhante à realizada. Em relação a aprendizagem dos estudantes, teve questões de como eles preferem trabalhar, em grupo ou individualmente. Também teve uma perspectiva bem direta e curta do estilo de aprendizagem VARK (Visual, Aural, Read/write, and Kinesthetic, ou no português Visual, Audição, Leitura/Escrita e Cinestésico), criado por Neil Fleming em 1992 [Fleming 2019], podendo identificar se o estudante aprende melhor discutindo, ouvindo, lendo, vendo ou praticando. No quesito de conteúdo e dos jogos, perguntamos sobre o quanto pensavam que poderiam saber sobre as habilidades do PC (abstração, decomposição e composição, raciocínio algorítmico e reconhecimento de padrões).

\section{Resultados e Discussões}

Essa proposta foi executada em uma oficina na SNCT no IFBA do campus Porto Seguro, para estudantes de ensino médio e superior da área da Computação. Nessa oficina participaram 13 estudantes ${ }^{7}$, que foram separados em grupos ou duplas para utilização dos jogos. Os dados tratados em gráficos e comentários ${ }^{8}$ do formulário, foram divididos e organizados em três blocos temáticos para melhor compreensão: 1) Perfil do Participante da Oficina; 2) Conteúdo e Desenvolvimento da Oficina e 3) Docente em Formação. Além disso, nesta secção o participante teve espaço para críticas e sugestões em cada bloco temático.

\subsection{Perfil do Participante da Oficina}

Considerando que, o fator emocional pode ser determinante à interiorização dos conteúdos. Perguntamos aos participantes como eles estavam se sentindo instantes antes

\footnotetext{
${ }^{6}$ Link de acesso ao formulário: https://bit.ly/questionario-avaliacao

${ }^{7}$ Link de acesso para as fotos da oficina: http://bit.ly/fotosdaoficina

${ }^{8}$ Link de acesso aos gráficos detalhados dos resultados do formulário: https://bit.ly/resultadodado
} 
IX Congresso Brasileiro de Informática na Educação (CBIE 2020)

Anais do XXXI Simpósio Brasileiro de Informática na Educação (SBIE 2020)

da sua participação na oficina, assim 50\% dos participantes afirmaram estar se sentindo ótimo ou bem.

Seguindo essa ideia de entender o perfil dos participantes, perguntamos à eles qual é a metodologia de ensino com a qual acreditam que podem aprender melhor de acordo com o estilo de aprendizagem VARK criado por Neil Fleming. Para tanto, apresentamos cinco opções objetivas, que são: 1- discutindo, 2- ouvindo, 3- vendo, 4- lendo e 5- praticando. As questões apresentadas tinham graduações de acordo com a escala likert $^{9}$, que partiam do número 1: péssimo, como mínimo, ao número 5: excelente, como máximo.

No quesito de aprendizagem discutindo, $50 \%$ dos entrevistados disseram que a aprendizagem é regular e os outros $50 \%$ responderam que essa é uma boa ou excelente forma para aprender um conteúdo. Para o item aprendizagem ouvindo, 62,5\% dos participantes disseram ser um meio péssimo, ruim ou regular para a aprendizagem e interiorizar os temas concebidos. Quando se trata do quesito estudar como expectador da execução de alguma atividade, 52,5\% afirmaram que essa é uma metodologia ruim ou regular para compreender o que foi posto. Com resultado semelhante, a prática de leitura foi considerada como péssima ou regular por $50 \%$ dos participantes. Em atividades práticas para a apresentação dos conteúdos, $62,5 \%$ consideram que, o desenvolvimento prático de atividades para ministrar os conteúdos é boa ou excelente metodologia.

As habilidades do PC também foram pesquisadas. Assim, obtivemos para a abstração, que $75 \%$ são bons para a referida habilidade ou pensam dominar essa competência com excelência. Quanto ao raciocínio algorítmico, 87,5\% disseram ser bons ou dominam essa competência com excelência. Para a habilidade decomposição e recomposição, $50 \%$ dos entrevistados disseram ser péssimo, deficiente ou se considera seu conhecimento regular, para os outros $50 \%$ pensam ser bons ou se diz ser excelente no entendimento desse talento. O reconhecimento de padrões foi a habilidade com maior domínio entre os participantes, com índice de $75 \%$ para os que pensam ser excelentes nessa capacidade.

Além do exposto, os participantes dissertaram sobre os motivos pelos quais escolheram participar da oficina. Obtivemos justificativas como: "Para entender o uso de jogos como auxiliar no ensino de computação e sua relação com o desenvolvimento do pensamento Computacional"; "Para aprender novos métodos de aprendizagem” ; outros responderam que acharam a ideia legal ou se inscreveram por curiosidade e outros apenas queriam jogar.

\subsection{Conteúdo e Desenvolvimento da Oficina}

A análise dos dados referente a eficiência da aplicação dos conteúdos ministrados e seu desenvolvimento, e, quanto o participante compreendeu do que foi posto. Pesquisamos entre os participantes, como eles se sentiram em relação aos conteúdos apresentados no decorrer das atividades, para esse quesito, $100 \%$ disseram que se sentiram confortavelmente excelente ou bem. Além disso, verificamos também o nível de satisfação dos participantes com relação a sua participação, $75 \%$ dos participantes afirmaram que, a oficina superou suas expectativas ou que ficaram satisfeitos.

Com relação a efetividade da aprendizagem utilizando jogos para o ensino de

\footnotetext{
${ }^{9}$ Escala de medida do nível de aceitação de uma afirmativa por meio de um questionário.
} 
IX Congresso Brasileiro de Informática na Educação (CBIE 2020)

Anais do XXXI Simpósio Brasileiro de Informática na Educação (SBIE 2020)

computação, pesquisamos se o conteúdo foi compreendido, $62,5 \%$ dos participantes afirmaram que tiveram uma excelente compreensão do que foi apresentado. Verificamos também se a metodologia utilizada promoveu um ambiente divertido na aplicação da oficina, cujo resultado foi de $100 \%$ de satisfação. Além do exposto, os participantes deixaram elogios e críticas com relação aos conteúdos e condução da oficina. Alguns participantes teceram elogios, como: "oficina foi muito bem pensada e também bem apresentada, conteúdo foi fácil de entender"; "achei impressionante a opção de utilizar jogos inclusivos"; "O pessoal foram legais e foi bem interessante da forma que ensinaram". Por outro lado, percebemos críticas também positivas, como: "Acredito que ficou meio vago a explicação dos jogos para o ensino da computação”; "[...]Poderia ser mais tempo".

\subsection{Docente em formação}

Para tanto realizamos um levantamento, por meio de formulário, com os participantes da oficina. Um dos quesitos levantados foi a segurança na condução da oficina pelos professores em formação, obtendo que para $62,5 \%$ dos participantes os docentes apresentaram um nível de segurança muito elevado. Quando perguntados se o vocabulário utilizado foi adequado ao conteúdo, $100 \%$ afirmaram que o vocabulário foi muito bem adequado ou bom. Averiguamos também, como perceberam o grau de conhecimento e compreensão dos conceitos e princípios do assunto abordado. Sendo assim, 100\% declararam que os graduandos atenderam os preceitos citados com excelência ou bom. Além disso, verificamos a utilização dos recursos disponíveis para o momento da oficina, na qual 87,5\% dos participantes afirmaram que, os futuros docentes utilizaram de forma excelente os recursos disponíveis. Com relação a avaliação continuada, 100\% afirmaram que os graduandos foram excelentes ou bem nesse tipo de avaliação.

Em face do que foi avaliado pelos participantes, foi propiciado um espaço para recomendações, elogios e críticas aos licenciandos. Com isso, destacamos alguns comentários, como: "foi observado que existia sincronia entre as falas e isso foi importante para o entendimento dos conteúdos apresentados"; "Gostei da apresentação, foi dinâmica e divertida sem fugir do que estava sendo apresentado"; "achei incrível a preocupação dos elaboradores em deixar todos os jogos de uma forma inclusiva e também a diversa quantidade de jogos, porém em alguns aspectos como por exemplo no UNO o jogo tava meio desorganizado, mas não muito, concluindo achei tudo legal”.

Os dados coletados demonstram mudanças positivas quanto ao entusiasmo, empatia, colaboração dos estudantes, em comparação ao antes da oficina a partir das observações dos licenciandos, e depois a partir de um formulário respondido pelos participantes, que, notou-se também maior interesse e motivação pelo ensino de Computação, principalmente pela utilização dos jogos. Em relação a oficina piloto, é válido mencionar que percebeu-se que, mesmo com estudantes de outra área, tendo em vista a participação de discentes de outro curso, Licenciatura em Química, a ação cumpriu com o seu objetivo. Além disso, mesmo que alguns estudantes não perceberam de imediato o conteúdo relacionado aos jogos, como também tiveram uma certa dificuldade no início ao praticar os jogos, com o tempo e a explanação dos docentes, puderam compreender melhor os assuntos abordados e então tornar mais natural o processo da oficina. Ademais, os discentes gostaram da postura dos professores de Computação em formação, essencialmente pela sensibilidade ao inserir a inclusão de deficientes visuais para o âmbito educacional, com 
IX Congresso Brasileiro de Informática na Educação (CBIE 2020)

Anais do XXXI Simpósio Brasileiro de Informática na Educação (SBIE 2020)

isso a socialização se torna mais frequente.

\section{Considerações Finais}

Considerando o exposto, percebemos que, a utilização de jogos se mostrou uma metodologia viável e de baixo custo para atenuar a ausência de estrutura digital. Além disso, os jogos podem ser considerados como eficaz para o desenvolvimento do PC e suas habilidades. Ademais, foi evidenciado que, essas habilidades favorecem o desempenho positivo de outros componentes curriculares, abordando assim a aprendizagem significativa, que traz uma maior facilidade para aprendizado do novo tema, pois alguns assuntos já foram trabalhados anteriormente em sua vida acadêmica ou por experiências. Essa oficina por meio dos jogos pode conduzir uma interação entre os discentes, já que muitos não se conheciam, assim trazendo uma atividade colaborativa para o aprendizado de forma lúdica, além de enfatizar a acessibilidade dos jogos. Além disso, é perceptível nos dados coletados que, são compatíveis com as observações tidas pelos licenciandos, em que a maioria se diz competente na habilidade de reconhecimento de padrões e isso é analisado de forma nítida durante a oficina.

Os dados analisados permitiram conceber que, a maioria dos estudantes preferem aulas práticas. Nessa análise, em relação ao quesito emocional dos discentes, percebe um aumento do nível de bem estar antes, durante e após a aplicação dos jogos. Em face disso, o processo de ensino aprendizagem por meio de jogos perpassa por um ambiente leve e descontraído, o qual propicia a significância dos conceitos abstratos da computação envolvendo acessibilidade de forma lúdica. Com isso, é fundamental sua importância, pois traz além do aprendizado ativo, a diversão para o meio que é colocado.

Dessa forma, por meio dos dados, os estudantes perceberam a importância que os docentes deram para a inclusão social, métodos e práticas para que possa trazer um aprendizado mais eficaz e ao mesmo tempo divertido, bem como a forma mediadora de direcionamentos, observações e avaliações que tornaram no processo da oficina, também o domínio da fala dos conteúdos trabalhados e a segurança do mesmo. Diante disso, a proposta da utilização de jogos se apresenta como mais um dispositivo favorável à inclusão social no ensino de Computação de forma eficaz. Uma vez que, permite uma maleabilidade maior para as instituições e docentes para trabalharem os conteúdos da Computação, a fim de promover um ambiente igualitário, mitigando o diferencial econômico, muitas vezes, determinante para o sucesso na construção dos saberes em nossa sociedade.

\section{Referências}

Bell, T., Witten, I. H., and Fellows, M. (2011). Ensinando Ciência da Computação sem o uso do computador. Disponível em: http://csunplugged.org/. Acessado em: $15 / 05 / 2020$.

Berssanette, J. H. and Francisco, A. C. D. (2018). Proposta de Abordagem Prática para o Ensino de Programação Baseada em Ausubel. Anais do XXIX Simpósio Brasileiro de Informática na Educação, (SBIE):398-407.

Brasil (1996). Lei $\mathrm{N}^{0}$ 9.394, de 20 de Dezembro de 1996. Disponível em: http://www.planalto.gov.br/ccivil_03/leis/19394.htm. Acessado em: 06/06/2020.
Brasil (2017).
Ministério
da Educação
- MEC
Base Nacional
Co- mum Curricular
Educação
é a Base - BNCC.
Disponível
em: 
IX Congresso Brasileiro de Informática na Educação (CBIE 2020)

Anais do XXXI Simpósio Brasileiro de Informática na Educação (SBIE 2020)

http://basenacionalcomum.mec.gov.br/images/BNCC_EI_EF_110518_versaofinal_site.pdf. Acessado em: 06/06/2020.

Constituição (1988). Constituição da República Federativa do Brasil de 1988. Disponível em: http://www.planalto.gov.br/ccivil_03/constituicao/constituicao.htm. Acessado em: 06/06/2020.

Cruz, S. M. S., Calé, F., Paim, L., Benassi, P., and Miranda, R. (2017). Uma ferramenta para auxiliar o ensino da Tecnologia da Informação para surdos. Anais dos Workshops do VI Congresso Brasileiro de Informática na Educação (CBIE 2017), 1(Cbie):244.

Fleming, N. D. (2019). VARK Strategies: The definitive guide to VARK.

Gavaza, L. O. R., Salvador, L. d. N., and Santos, D. M. B. (2018). Percepção de estudantes sobre motivação e aprendizagem em Teoria da Computação com PBL. Anais do XXVI workshop sobre educação em computação, (WEI).

Guarda, G. F. and Goulart, I. F. (2018). Jogos Lúdicos sob a ótica do Pensamento Computacional: Experiências do Projeto Logicamente. Anais do XXIX Simpósio Brasileiro de Informática na Educação, (SBIE):486-495.

IBGE (2015). Pesquisa Nacional de Saúde - PNS, 2015. Disponível em: https://www.ibge.gov.br/busca.html?searchword=pns. Acessado em: 06/06/2020.

IBGE (2019). Projeção da população do Brasil 2019. Disponível em: https://www.ibge.gov.br/apps/populacao/projecao/. Acessado em: 06/06/2020.

MEC (2019). Instituto Nacional de Estudos e Pesquisas Educacionais Anísio Teixeira INEP. Disponível em: http://portal.inep.gov.br/web/guest/resultados-e-resumos. Acessado em: 06/06/2020.

Nery, É. S. S. and Sá, A. V. M. (2019). A deficiência visual em foco: estratégias lúdicas na Educação Matemática Inclusiva. Revista Educação Especial, 32.

Pereira, F. T. S. S., Araújo, L. G. J., and Bittencourt, R. A. (2019). Intervenções de Pensamento Computacional na Educação Básica através de Computação Desplugada. Anais do XXV Workshop de Informática na Escola, (WIE):315-324.

Reis, R. C. D., Lyra, K. T., Reis, C. D. G., and Isotani, S. (2018). Relato de Experiência sobre o uso da Computação Desplugada associada a uma Teoria de Aprendizagem Colaborativa. Anais do XXIV Workshop de Informática na Escola, (WIE):166-175.

Santos, J. C. O. and Figueiredo, K. d. S. (2016). Computasseia: Um Jogo para o Ensino de História da Computação. Anais do XXIV workshop sobre educação em computação, pages 2026-2035.

Silva, D. J. G. M., Guarda, G. F., and Goulart, I. F. (2018). CriptoLab: Um game baseado em Computação Desplugada e Criptografia. Anais do XXVI workshop sobre educação em computação.

Vieira, A. S., Sousa, L. S., Belarmino, J. R., and Sales, E. S. (2019). Discentes com Necessidades Especiais e os Desafios no Ensino de Algoritmos com Atividades Colaborativa e Competitiva : as regras do jogo na sala de aula. Anais dos Workshops do VIII Congresso Brasileiro de Informática na Educação, (WCBIE):475-484.

Wing, J. M. (2006). Computational Thinking. Viewpoint, 49(3):33-35. 